JURNAL KACAPURI

JURNAL KEILMUAN TEKNIK SIPIL

Volume 4 Nomor 2 Edisi Desember 2021

\title{
STUDI EVALUASI DAYA DUKUNG ULTIMIT PONDASI TIANG PANCANG TUNGGAL BERDASARKAN DATA CPT PADA PEMBANGUNAN GEDUNG BARU UNISKA HANDIL BAKTI KABUPATEN BARITO KUALA
}

\author{
Akhmad Gazali ${ }^{1 *}$, Muhammad Gunawan Perdana ${ }^{2)}$, Tezar Aulia Rachman ${ }^{3)}$ \\ (1), (2), (3) Dosen Program Studi Teknik Sipil, Fakultas Teknik, Universitas Islam Kalimantan MAB \\ Email: akhmadgazali51@gmail.com
}

\begin{abstract}
ABSTRAK
Pondasi merupakan elemen struktur bangunan bawah tanah yang sangat penting dalam suatu pekerjaan konstruksi bangunan, karena pondasi inilah yang berfungsi sebagai penopang bangunan dan meneruskan beban yang berasal dari berat bangunan itu sendiri dan beban yang bekerja pada bangunan ke lapisan tanah disekitarnya yang cukup kuat daya dukungnya. Selain itu, menyangkut masalah ketahanan bangunan tergantung pada jenis pondasi yang akan digunakan. Salah satu jenis pondasi yang sering digunakan untuk bangunan tinggi adalah pondasi tiang pancang. Pondasi tiang pancang atau disebut juga pondasi dalam dipergunakan untuk konstruksi beban berat (high rise building). Tujuan dari Penelitian ini untuk menghitung nilai daya dukung ultimit teoritis dan daya dukung ijin teoritis tiang pancang tunggal berdasarkan data Cone Penetration Tests (CPT), selanjutnya membandingkan hasil daya dukung ultimit teoritis dan daya dukung ijin teoritis tiang pancang tunggal dengan beberapa metode. Metodologi pengumpulan data dilakukan dengan cara melakukan observasi, pengambilan data dari pihak proyek serta melakukan studi literatur ke perpustakaan. Pada perhitungan daya dukung tiang pancang tunggal dilakukan dengan menggunakan beberapa metode yaitu metode Meyerhof dengan metode Price \& Wardle. Berdasarkan hasil perhitungan diperoleh kapasitas daya dukung ultimit pondasi mini pile menggunakan Metode Mayerhoff sebesar $\mathrm{Qu}_{1}=188,82$ ton pada sondir 1 (S-1), $\mathrm{Qu}_{2}=214,62$ ton pada sondir 2 (S-2) dan $\mathrm{Qu}_{3}=230,95$ ton pada sondir 3 (S-3). Sedangkan berdasarkan hasil perhitungan kapasitas daya dukung ultimit pondasi mini pile menggunakan Metode Price \& Wardle sebesar $\mathrm{Qu}_{1}=$ 347,72 ton pada sondir $1(\mathrm{~S}-1), \mathrm{Qu}_{2}=433,18$ ton pada sondir $2(\mathrm{~S}-2)$ dan $\mathrm{Qu}_{3}=487,29$ ton pada sondir $3(\mathrm{~S}-3)$.
\end{abstract}

Kata Kunci: Daya Dukung Ultimit, Pondasi Tiang Pancang, CPT, Kabupaten Barito Kuala

\section{ABSTACT}

The foundation is a structural element of an underground building that is very important in a building construction work, because it is this foundation that functions as a support for the building and transmits the load that comes from the weight of the building itself and the load acting on the building to the surrounding soil layer which has a strong enough carrying capacity. In addition, regarding the issue of building durability, it depends on the type of foundation to be used. One type of foundation that is often used for high-rise buildings is the pile foundation. Pile foundations or also called deep foundations are 
JURNAL KACAPURI

used for heavy load construction (high rise building). The purpose of this study is to calculate the value of the theoretical ultimate bearing capacity and the theoretical permit bearing capacity of a single pile based on Cone Penetration Tests (CPT) data, then compare the results of the theoretical ultimate bearing capacity and the theoretical permit bearing capacity of a single pile with several methods. The methodology of data collection was carried out by observing, collecting data from the project and conducting literature studies to the library. The calculation of the carrying capacity of a single pile is carried out using several methods, namely the Meyerhof method with the Price \& Wardle method. Based on the calculation results, the ultimate bearing capacity of the mini pile foundation using the Mayerhoff method is $Q u 1=188.82$ tons on sondir $1(S-1), Q u 2=214.62$ tons on sondir $2(S-2)$ and $Q u 3=230.95$ tons on sondir $3(S-3)$. Meanwhile, based on the results of the calculation of the ultimate bearing capacity of the mini pile foundation using the Price \& Wardle method, Qu1 = 347.72 tons on sondir 1 (S-1), Qu2 $=433.18$ tons on sondir $2(S-2)$ and $Q u 3=487.29$ tons on sondir $3(S-3)$.

Keywords: Ultimate Bearing Capacity, Pile Foundation, CPT, Barito Kuala District

\section{PENDAHULUAN}

Dalam bidang Teknik Sipil, tanah merupakan dasar dari suatu pembangunan konstruksi. Tanah diharapkan dapat menahan pembebanan yang bekerja di atasnya. Perencanaan yang matang sangat diperlukan, guna menghasilkan suatu konstruksi yang stabil, aman dan ekonomis. Pada kegiatan pembangunan infrastruktur jalan maupun gedung, pondasi merupakan bagian sangat penting dari suatu bangunan sipil. Pondasi sebagai dasar penahan beban paling bawah dari suatu konstruksi. Pondasi adalah struktur bagian bawah bangunan yang berhubungan langsung dengan tanah, atau bagian bangunan yang terletak dibawah permukaan tanah yang mempunyai fungsi memikul beban bagian bangunan diatasnya.

Pondasi ada dua jenis, yaitu pondasi dangkal dan pondasi dalam. Pondasi dangkal adalah pondasi yang tidak membutuhkan galian tanah yang terlalu dalam karena lapisan tanah dangkal sudah cukup keras. Sedangkan pondasi dalam adalah pondasi yang membutuhkan pengeboran atau pemancangan dalam karena lapisan tanah yang keras berada dikedalaman cukup dalam, seperti pondasi pada bangunan jembatan. Salah jenis pondasi dalam adalah pondasi tiang.

Secara umum permasalahan pondasi dalam lebih rumit dari pondasi dangkal. Pondasi tiang pancang merupakan salah satu jenis pondasi dalam yang umum digunakan. Tiang ini berfungsi untuk menyalurkan beban struktur ke lapisan tanah keras yang mempunyai kapasitas daya dukung tinggi yang letaknya yang cukup dalam di dalam tanah. Dalam pondasi, terdapat sebuah analisis berupa kapasitas daya dukung pondasi yang merupakan analisa kekuatan pondasi untuk menahan sutau beban yang bekerja padanya yang biasanya disalurkan melalui pondasi. Tujuan analisis daya dukung pondasi tersebut adalah untuk mengetahui berapa beban yang dapat diterima oleh suatu pondasi dengan tidak melebihi kapasitas ijin dari pondasi tersebut.

Berlatar belakang hal tersebut di atas, maka maksud dan tujuan dari penelitian ini adalah untuk menganalisis dan mengevaluasi nilai daya dukung ultimit teoritis dan nilai daya dukung ijin teoritis pondasi tiang pancang tunggal berdasarkan data Cone Penetration Test (CPT) menggunakan Metode 
JURNAL KACAPURI

JURNAL KEILMUAN TEKNIK SIPIL

Volume 4 Nomor 2 Edisi Desember 2021

Meyerhof dan Metode Price \& Wardle pada Pembangunan Gedung Baru Uniska Handil Bakti Kabupaten Barito Kuala.

\section{TINJAUAN PUSTAKA}

\section{Definisi Pondasi}

Secara umum pondasi merupakan bangunan bawah tanah yang dapat meneruskan beban-beban dari atas dan beratnya sendiri kedalam lapisan tanah tanpa terjadi keruntuhan, geser tanah, dan penurunan tanah. Pekerjaan struktur pondasi merupakan pekerjaan struktur bawah. Pondasi harus mampu mendukung beban sampai batas keamanan yang telah ditentukan, termasuk mendukung beban maksimum yang mungkin terjadi. Jenis pondasi yang sesuai dengan tanah pendukung terletak pada kedalaman 10 meter dibawah permukaan tanah yaitu pondasi tiang. (Dr. Ir. Suryono Sosrodarsono dan Kasuta Nakasawa, 1990).

Menurut Das (1988), tanah didefinisikan sebagai material yang terdiri dari agregat (butiran) mineralmineral padat yang tersementasi (terikat secara kimia) satu sama lain dan dari bahan-bahan organik yang telah melapuk (yang berpatikel padat) disertai dengan zat cair dan gas yang mengisi ruang-ruang kosong antara partikel-partikel padat tersebut. Pondasi merupakan struktur pendukung utama dari struktur yang berfungsi meneruskan dan menyebarkan beban yang diterimanya dari struktur atas bangunan kelapisan tanah pendukung, fungsinya untuk menahan beban bangunan yang ditimbulkan oleh konstruksi yang berada diatasnya tanpa mengakibatkan:

1. Keruntuhan geser tanah

2. Penurunan tanah/pondasi yang berlebihan.

\section{Jenis-Jenis Pondasi}

Secara garis besar pondasi dibedakan menjadi 2 (dua) macam yaitu sebagai berikut:

a. Pondasi Dangkal

Pondasi dangkal adalah pondasi yang mendukung beban secara langsung. Pada umumnya, pondasi dikatakan pondasi dangkal jika D/B < 1. Dimana D adalah kedalaman pondasi dan B adalah lebar pondasi. Tanah pendukung pondasi terletak pada permukaan tanah atau kedalaman 2-3 m kebawah permukaan tanah.

b. Pondasi Dalam

Pondasi dalam merupakan pondasi yang meneruskan beban bangunan ketanah keras atau batu yang terletak relative jauh dari permukaan. Pondasi dalam digunakan bila lapisan tanah didasar pondasi tidak mampu mendukung beban yang dilimpahkan dan terletak cukup dalam. Atau dengan pertimbangan adanya pengerusan dan galian dekat pondasi dikemudian hari. Umumnya dikatakan pondasi dalam apabila $\mathrm{D}>4 \mathrm{~B}$ sampai $5 \mathrm{~B}$.

\section{Analisis Daya Dukung Ultimit Pondasi Tiang Menggunakan Data Cone Penetration Test (CPT)}

Diantara perbedaaan tes di lapangan, data Cone Penetration Test (CPT) atau sondir sering kali sangat dipertimbangkan berperanan dari geoteknik. CPT atau sondir ini tes yang sangat cepat, sederhana, 
JURNAL KACAPURI

ekonomis dan tes tersebut dapat dipercaya dilapangan dengan pengukuran terus-menerus dari permukaan tanah-tanah dasar. CPT atau sondir ini dapat juga mengklasifikasi lapisan tanah dan dapat memperkirakan kekuatan dan karakteristik dari tanah. Didalam perencanaan pondasi tiang pancang, data tanah sangat diperlukan dalam merencanakan kapasitas daya dukung (bearing capacity) dari tiang pancang sebelum pembangunan dimulai, guna menentukan kapasitas daya dukung ultimit dari tiang pancang. Kapasitas daya dukung ultimit ditentukan dengan persamaan sebagai berikut :

$$
\mathrm{Qu}=\mathrm{Qb}+\mathrm{Qs}
$$

Dimana:

$\mathrm{Qu}=$ Kapasitas daya dukung aksial ultimit tiang pancang.

$\mathrm{Qb}=$ Kapasitas tahanan di ujung tiang.

Qs = Kapasitas tahanan kulit.

$\mathrm{Qb}=$ Kapasitas daya dukung di ujung tiang persatuan luas.

$\mathrm{Ab}=$ Luas di ujung tiang.

$\mathrm{f}=$ Satuan tahanan kulit persatuan luas.

As $=$ Luas kulit tiang pancang.

\section{Daya Dukung Ultimit Teoritis Pondasi Tiang Pancang Menggunakan Metode Meyerhof}

Untuk menghitung daya dukung pondasi tiang pancang berdasarkan data hasil pengujian sondir, dapat dilakukan dengan menggunakan metode Meyerhof. Daya dukung ultimit teoritis pondasi tiang pancang dinyatakan dengan rumus :

Qult $=(q \mathrm{q} \times \mathrm{Ap})+(\mathrm{JHL} \times \mathrm{K} 11)$

Dimana:

Qult = Kapasitas daya dukung tiang pancang tunggal.

qc $=$ Tahanan ujung sondir.

Ap = Luas penampang tiang.

$\mathrm{JHL}=$ Jumlah hambatan lekat.

K11 = Keliling tiang.

Daya dukung ijin teoritis pondasi tiang pancang dinyatakan dengan rumus:

$$
\text { Qijin }=\frac{q c A p}{3}+\frac{J H L \times K 11}{5} \text {. }
$$

Dimana:

Qijin = Kapasitas daya dukung ijin pondasi.

$\mathrm{qc} \quad=$ Tahanan ujung sondir.

Ap = Luas penampang tiang.

\section{Daya Dukung Ultimit Teoritis Pondasi Tiang Pancang Menggunakan Metode Price \& Wardle}

Kontribusi lain dalam pengembangan korelasi langsung untuk memprediksi komponen daya dukung berdasarkan data CPT adalah metode Price dan Wardle (1982), dimaksudkan untuk memprediksi qb dan $\mathrm{f}_{\mathrm{p}}$ tiang dari data CPT yaitu $\mathrm{q}_{\mathrm{c}}$ dan $\mathrm{f}_{\mathrm{c}}$.

Komponen daya dukung tersebut diperoleh dengan :

$$
\begin{aligned}
& \mathrm{f}_{\mathrm{p}}=\mathrm{k}_{\mathrm{S}} \cdot \mathrm{f}_{\mathrm{S}} \ldots \\
& \mathrm{q}_{\mathrm{b}}=\mathrm{k}_{\mathrm{b}} \cdot \mathrm{q}_{\mathrm{c}} \text { (tip) }
\end{aligned}
$$


Dimana:

$\mathrm{f}_{\mathrm{p}}=$ Tahanan selimut tiang $\left(\mathrm{ton} / \mathrm{m}^{2}\right)$

$\mathrm{f}_{\mathrm{S}}=$ Bacaan gesekan selimut konus (ton $/ \mathrm{m}^{2}$ )

$\mathrm{k}_{\mathrm{S}}$ dan $\mathrm{kb}=$ Konstanta bergantung pada jenis tiang

$\mathrm{qb}=$ Tahanan ujung tiang (ton $/ \mathrm{m}^{2}$ )

$\mathrm{q}_{\mathrm{c}}(\mathrm{tip})=$ nilai $\mathrm{q}_{\mathrm{c}}$ pada ujung tiang $\left(\mathrm{ton} / \mathrm{m}^{2}\right)$

Tabel 1. Variasi nilai $\mathrm{k}_{\mathrm{S}}$

\begin{tabular}{|c|c|}
\hline $\mathbf{k}_{\mathbf{S}}$ & Jenis Tiang \\
\hline 0,53 & Driven piles \\
\hline 0,62 & Jacked piles \\
\hline 0,49 & Drilled shaft \\
\hline
\end{tabular}

Sumber: Evaluasi Formula Penentuan Daya Dukung Aksial Tiang Pancang Tunggal, 2014

Tabel 2. Variasi nilai $\mathrm{kb}$

\begin{tabular}{|c|c|}
\hline $\mathbf{k b}$ & Jenis Tiang \\
\hline 0,35 & Driven piles \\
\hline 0,30 & Jacked piles \\
\hline
\end{tabular}

Sumber: Evaluasi Formula Penentuan Daya Dukung Aksial Tiang Pancang Tunggal, 2014

Untuk kapasitas daya dukung ultimit tiang digunakan persamaan :

$$
\mathrm{Qu}=\mathrm{Qb}+\mathrm{Qs}=\mathrm{qb} \cdot \mathrm{Ab}+\mathrm{fb} \cdot \mathrm{As}
$$

Dimana:

$\mathrm{Qu}=$ Kapasitas daya dukung aksial ultimit tiang pancang

$\mathrm{Qb}=$ Kapasitas tahanan di ujung tiang

Qs = Kapasitas tahanan kulit

$\mathrm{qb}=$ Kapasitas daya dukung di ujung tiang persatuan luas

$\mathrm{Ab}=$ Luas diujung tiang

$\mathrm{fb}=$ Satuan tahanan kulit persatuan luas,

As $=$ Luas kulit tiang pancang

\section{METODE PENELITIAN}

\section{Lokasi Penelitian}

Adapun lokasi penelitian ini berada Jl. Trans Kalimantan KM. 0,2 Komplek Perumahan Agrabudi, Kecamatan Alalak, Kabupaten Barito Kuala Provinsi Kalimantan Selatan.

\section{Tahapan Penyusunan Penelitian}

Metode penelitian yang digunakan dalam penyusunan penelitian ini ialah metode eksperimental yaitu dengan melakukan observasi terhadap suatu kondisi buatan (manipulasi terhadap objek penelitian) yang kemudian hasilnya akan dibandingkan dengan suatu kontrol. Dalam pelaksanaan metode penelitian yang 
JURNAL KACAPURI

JURNAL KEILMUAN TEKNIK SIPIL Volume 4 Nomor 2 Edisi Desember 2021

dilakukan terdiri dari beberapa tahap, antara lain: tahap persiapan; tahap pengumpulan data dan literatur; tahap analisis data; dan tahap kesimpulan.

\section{Bagan Alir Penelitian}

Bagan alir dari penelitian ini dapat dilihat pada Gambar 1 di bawah ini.

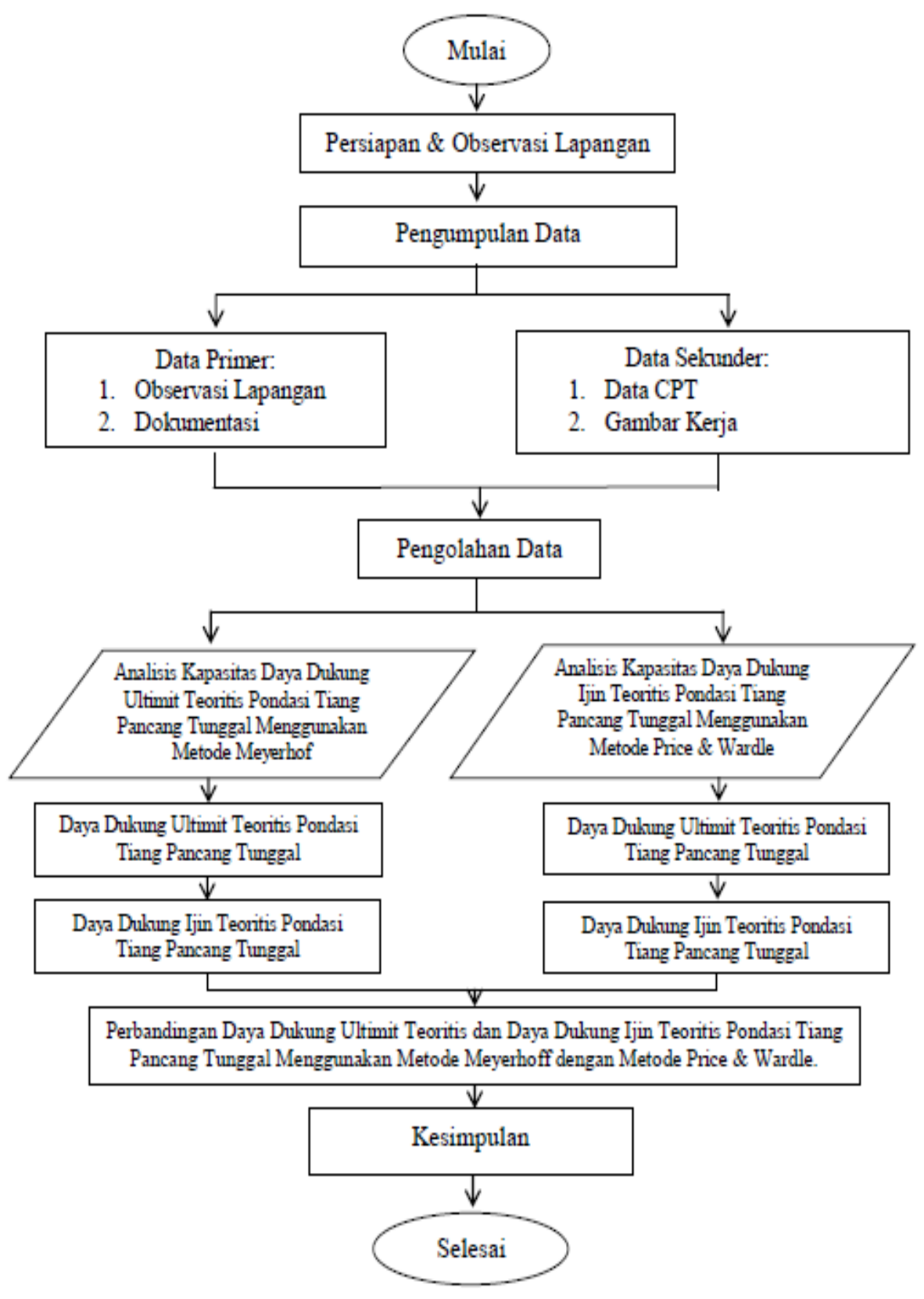

Gambar 1. Bagan Alir Penelitian

\section{HASIL DAN PEMBAHASAN}

Tinjauan Penelitian 
Pada penelitian ini peneliti mengambil tempat yang berlokasi pada Jl. Trans Kalimantan KM. 0,2 Komplek Perumahan Agrabudi, Kecamatan Alalak, Kabupaten Barito Kuala Provinsi Kalimantan Selatan. Bangunan Gedung Baru UNISKA Handil Bakti memiliki 4 (empat) lantai dengan panjang 37,50 $\mathrm{m}$ dan lebar 18,0 $\mathrm{m}$ sehingga luasnya adalah $675 \mathrm{~m}^{2}$.

\section{Spesifikasi Tiang Pancang}

Pondasi tiang pancang yang digunakan dalam Pembangunan Gedung Baru UNISKA Handil Bakti adalah Bentuk penampang tiang pancang adalah persegi (square) dengan dimensi penampang $25 \times 25 \mathrm{~cm}$, dengan panjang bervariasi mulai $38,8 \mathrm{~m}$ sampai dengan $40,0 \mathrm{~m}$ dan mutu beton yang digunakan adalah K-500.

\section{Data Hasil Penyelidikan Tanah}

Berdasarkan hasil penyelidikan tanah berupa sondir sebanyak 3 (tiga) titik pada Pembangunan Gedung Baru UNISKA Handil Bakti ini diperoleh data kedalaman tanah keras berada pada kedalaman 38,8 m untuk sondir 1 (S-1), kedalaman 39,20 m untuk sondir 2 (S-2) dan kedalaman 40,00 m untuk sondir 3 (S-3). Untuk hasil rekapitulasi penyelidikan tanah dapat dilihat pada Tabel 3 di bawah ini:

Tabel 3. Hasil Rekapitulasi Penyelidikan Tanah

\begin{tabular}{|c|c|c|c|c|c|c|}
\hline \multirow{2}{*}{ No. } & \multirow{2}{*}{ Titik } & \multicolumn{2}{|c|}{ Titik Koordinat } & \multirow{2}{*}{$\begin{array}{c}\text { Kedalaman } \\
\text { (m) }\end{array}$} & \multirow{2}{*}{$\begin{array}{c}\text { Nilai Konus, } \\
\text { qc }\left(\mathbf{k g} / \mathrm{cm}^{2}\right)\end{array}$} & \multirow{2}{*}{$\begin{array}{c}\text { Jumlah Hambatan } \\
\text { Lekat }(\mathrm{kg} / \mathrm{cm})\end{array}$} \\
\hline & & $\mathbf{X}$ & $\mathbf{Y}$ & & & \\
\hline 1 & S-1 & 232586 & 9638479 & 38,8 & 150 & 950,67 \\
\hline 2 & $\mathrm{~S}-2$ & 232615 & 9638479 & 39,2 & 150 & 1208,67 \\
\hline 3 & S-3 & 232602 & 9638486 & 40,0 & 150 & 1327,00 \\
\hline
\end{tabular}

Sumber: Laporan Penyelidikan Tanah

\section{Analisis Kapasitas Daya Dukung Pondasi Tiang Tunggal Menggunakan Metode Meyerhof}

Peneliti akan mengaplikasikan metode perhitungan daya dukung Meyerhof yang telah pada tinjaun pustaka. Daya dukung tiang akan dihitung dengan menggunakan data hasil sondir sebanyak 3 (tiga) titik yaitu tahanan ujung (qc) dan gesekan selimut tiang (fs). Adapun contoh perhitungan sebagai berikut:

\section{Data Sondir S-1}

1. Kedalaman $(\mathrm{d})=38,80 \mathrm{~m}$

2. Posisi di permukaan tanah galian

3. Hasil sondir dapat dilihat pada Tabel 3.

Data yang diperoleh dari titik 1 pada kedalaman 38,80 m adalah:

Perlawanan Penetrasi Konus (PPK), qc $=150 \mathrm{~kg} / \mathrm{cm}^{2}$

Jumlah Hambatan Lekat (JHL) $=950,67 \mathrm{~kg} / \mathrm{cm}$

Ukuran pondasi tiang $=25 \mathrm{~cm} \times 25 \mathrm{~cm}$

Luas Penampang Tiang $\left(\right.$ Ap) $=$ sisi $x$ sisi $=25 \mathrm{~cm} \times 25 \mathrm{~cm}=625 \mathrm{~cm}^{2}$

Keliling pondasi tiang $(\mathrm{K})=4 \times \mathrm{S}=4 \times 25=100 \mathrm{~cm}$

Daya dukung terhadap kekuatan tanah untuk tiang desak: Daya dukung tiang ultimit teoritis pada kedalaman 38,80 m.

$$
\begin{aligned}
& \text { Qult }=(\text { qc } \times \text { Ap })+(\text { JHL } \times \text { K }) \\
& \text { Qult }=(150 \times 625)+(950,67 \times 100)
\end{aligned}
$$




$$
\begin{aligned}
& =93.750+95.067 \\
& =188.817 \mathrm{~kg} \\
& =188,817 \mathrm{ton}
\end{aligned}
$$

Daya dukung tiang ijin teoritis (Q ijin)

$$
\begin{aligned}
\text { Q ijin } & =(\mathrm{qc} \times \mathrm{Ap}) / \mathrm{SF} 1+(\mathrm{JHL} \times \mathrm{K}) / \mathrm{SF} 2 \\
& =(150 \times 625) / 3+(950,67 \times 100) / 5 \\
& =31.250+19.013,4 \\
& =50.263,4 \mathrm{~kg} \\
& =50,2634 \mathrm{ton}
\end{aligned}
$$

\section{Analisis Kapasitas Daya Dukung Pondasi Tiang Tunggal Menggunakan Metode Price \& Wardle} Peneliti akan mengaplikasikan metode perhitungan daya dukung berdasarkan data sondir adalah metode Price dan Wardle (1982), dimaksudkan untuk memprediksi qb dan fp tiang dari data sondir yaitu qc dan fc. Adapun contoh perhitungan sebagai berikut:

\section{Data Sondir S-1}

1. Kedalaman $(\mathrm{d})=38,80 \mathrm{~m}$

2. Posisi di permukaan tanah galian

3. Hasil penyelidikan tanah (sondir) dapat dilihat pada Tabel 3

Contoh perhitungan:

Data yang diperoleh dari titik 1 pada kedalaman $38,80 \mathrm{~m}$ adalah:

Nilai qc pada ujung tiang, qc (tip) $=150 \mathrm{~kg} / \mathrm{cm}^{2}=1.500 \mathrm{ton} / \mathrm{m}^{2}$

Gesekan selimut konus (fs) $=950,67 \mathrm{~kg} / \mathrm{cm}^{2}=9.506,7 \mathrm{ton} / \mathrm{m}^{2}$

Ukuran pondasi tiang $=25 \mathrm{~cm} \times 25 \mathrm{~cm}$

$\mathrm{ks}=0,53$ (Diperoleh dari Tabel 1, jenis tiang Driven Piles)

$\mathrm{kb}=0,35$ (Diperoleh dari Tabel 2, jenis tiang Driven Piles)

Luas di ujung tiang $(\mathrm{Ab})=25 \times 25=625 \mathrm{~cm}^{2}=0,0625 \mathrm{~m}^{2}$

Luas selimut tiang $(\mathrm{As})=25 \times 25=625 \mathrm{~cm}^{2}=0,0625 \mathrm{~m}^{2}$

Daya dukung terhadap kekuatan tanah untuk tiang mini pile: Daya dukung tiang ultimit pada kedalaman $38,80 \mathrm{~m}$.

$$
\begin{aligned}
& \mathrm{Qu}=\mathrm{Qb}+\mathrm{Qs} \\
& \mathrm{Qu}=\mathrm{qb} \cdot \mathrm{Ab}+\mathrm{fb} \cdot \mathrm{As} \\
& \mathrm{Qu}=(\mathrm{kb} \cdot \mathrm{qc}(\mathrm{tip}) . \mathrm{Ab})+(\mathrm{ks} . \mathrm{fs}) . \mathrm{As} \\
& \mathrm{Qu}=(0,35.1500 \cdot 0,0625)+(0,53 \cdot 9 \cdot 506,7 \cdot 0,0625) \\
& \mathrm{Qu}=32,8125+314,909 \\
& \mathrm{Qu}=347,722 \text { ton }
\end{aligned}
$$

Daya dukung tiang ijin (Q ijin)

$\mathrm{Q}$ ijin $=\mathrm{Qu} / \mathrm{SF} \quad($ Asumsi SF $=3)$

$$
\begin{aligned}
& =347,722 / 3 \\
& =115,91 \text { ton }
\end{aligned}
$$

Perbandingan Daya Dukung Pondasi Tiang Menggunakan Metode Mayerhof dengan Metode Price \& Wardle 
JURNAL KACAPURI

JURNAL KEILMUAN TEKNIK SIPIL

Volume 4 Nomor 2 Edisi Desember 2021

Berdasarkan pada perhitungan sebelumnya dapat diketahui perbandingan nilai kapasitas daya dukung pondasi tiang menggunakan metode Mayerhoff dengan metode Price \& Wardle dapat disimpulkan pada Tabel 4 di bawah ini:

Tabel 4. Perbandingan Daya Dukung Pondasi Tiang Metode Mayerhoff dengan Metode Price \& Wardle

\begin{tabular}{|c|c|c|c|c|c|c|}
\hline \multirow{2}{*}{ No. } & \multirow{2}{*}{ Sondir } & \multirow{2}{*}{$\begin{array}{c}\text { Kedalaman } \\
(\mathbf{m})\end{array}$} & \multicolumn{2}{|c|}{ Metode Meyerhof } & \multicolumn{2}{c|}{ Metode Price \& Wardle } \\
\cline { 4 - 7 } & & Qu (ton) & $\mathbf{Q}_{\text {ijin }}($ ton) & Qu (ton) & Q $_{\text {ijin }}$ (ton) \\
\hline 1 & S-1 & 38,80 & 188,82 & 50,26 & 347,72 & 115,91 \\
\hline 2 & S-2 & 39,20 & 214,62 & 55,42 & 433,18 & 144,39 \\
\hline 3 & S-3 & 40,00 & 230,95 & 58,69 & 487,29 & 162,43 \\
\hline
\end{tabular}

Sumber: Hasil Perhitungan

Dari Tabel 4 di atas dapat disimpulkan bahwa nilai kapasitas daya dukung pondasi tiang menggunakan metode Price \& Wardle lebih besar daripada metode Meyerhof baik pada sondir 1 (S-1), sondir 2 (S-2) dan sondir 3 (S-3). Sehingga hasil yang mendekati dengan kenyataan adalah metode Meyerhof.

\section{PENUTUP}

\section{Kesimpulan}

Berdasarkan hasil pembahasan dalam penelitian, dapat ditarik kesimpulan sebagai berikut:

1. Berdasarkan hasil perhitungan diperoleh nilai daya dukung ultimit teoritis pondasi tiang pancang tunggal berdasarkan data Cone Penetration Test (CPT) menggunakan Metode Meyerhof sebesar Qu1 $=188,82$ ton pada sondir $1(\mathrm{~S}-1), \mathrm{Qu} 2=214,62$ ton pada sondir $2(\mathrm{~S}-2)$ dan $\mathrm{Qu} 3=230,95$ ton pada sondir 3 (S-3), sedangkan nilai daya dukung ultimit teoritis pondasi tiang pancang tunggal berdasarkan data Cone Penetration Test (CPT) menggunakan Metode Price \& Wardle sebesar Qu1 = 347,72 ton pada sondir $1(\mathrm{~S}-1), \mathrm{Qu} 2=433,18$ ton pada sondir $2(\mathrm{~S}-2)$ dan $\mathrm{Qu} 3=487,29$ ton pada sondir $3(\mathrm{~S}-3)$.

2. Berdasarkan hasil perhitungan diperoleh nilai daya dukung ijin teoritis pondasi tiang pancang tunggal berdasarkan data Cone Penetration Test (CPT) menggunakan Metode Meyerhof sebesar Qijin1 = 50,26 ton pada sondir 1 (S-1), Qijin2 = 55,42 ton pada sondir 2 (S-2) dan Qijin3 = 58,69 ton pada sondir 3 (S-3), sedangkan nilai daya dukung ijin teoritis pondasi tiang pancang tunggal berdasarkan data Cone Penetration Test (CPT) menggunakan Metode Price \& Wardle sebesar Qijin1 = 115,91 ton pada sondir 1 (S-1), Qijin2 = 144,39 ton pada sondir 2 (S-2) dan Qijin3 = 162,43 ton pada sondir 3 (S-3).

3. Berdasarkan hasil perhitungan dapat disimpulkan bahwa perbandingan nilai daya dukung ultimit teoritis pondasi tiang pancang tunggal menggunakan Metode Mayerhof dengan Metode Price \& Wardle adalah nilai daya dukung pondasi tiang pancang tunggal menggunakan metode Price \& Wardle lebih besar daripada metode Meyerhof baik pada sondir 1 (S-1), sondir 2 (S-2) dan sondir 3 (S-3), Sehingga hasil yang mendekati dengan kenyataan adalah metode Meyerhof.

4. Berdasarkan hasil perhitungan dapat disimpulkan bahwa perbandingan nilai daya dukung ijin teoritis pondasi tiang pancang tunggal menggunakan Metode Mayerhof dengan Metode Price \& Wardle adalah nilai daya dukung pondasi tiang pancang tunggal menggunakan metode Price \& Wardle lebih besar daripada metode Meyerhof baik pada sondir 1 (S-1), sondir 2 (S-2) dan sondir 3 (S-3), Sehingga hasil yang mendekati dengan kenyataan adalah metode Meyerhof. 
JURNAL KACAPURI

JURNAL KEILMUAN TEKNIK SIPIL

Volume 4 Nomor 2 Edisi Desember 2021

\section{DAFTAR PUSTAKA}

Agata Iwan Candra. 2017. Analisis Daya Dukung Pondasi Strauss Pile Pada Pembangunan Gedung Mini Hospital. Universitas Kadiri.Ukarst 1:1.

Akhmad Gazali, 2019. Analisis Kapasitas Daya Dukung Pondasi Tiang Pancang: Studi Kasus Proyek Pembangunan Pltu Sampit 2x25 Mw. Edisi Khusus: Prosiding Seminar Nasional Keinsinyuran, Buletin Profesi Insinyur 2(3) Issn 2654-5926. Teknik Sipil, Fakultas Teknik, Universitas Islam Kalimantan.

Akhmad Gazali, Fathurrahman, Yuli Wahyudi,2018. Analisis Kapasitas Daya Dukung Pondasi Tiang Pancang Dengan Pembebanan Vertikal Menggunakan Program Staad Pro V8i Pada Proyek Pembangunan Rumah Sakit Kelas D Kecamatan Kintap Kabupaten Tanah Laut. Jurnal Kacapuri Jurnal Keilmuan.

Anggun , Riswiyanto. 2018. Study Analisis Daya Dukung Pondasi Tiang Pancang Berdasarkan Data Sondir Dan Data Kalendering Pada Bangunan Gedung Asrama Blk Provinsi Kalimantan Timur. Jurnal Sipil Statik Vol.6 No.12 Desember 2018 (1029-1034) Issn: 2337-6732.

Arif Afriyanto. 2017. Analisa Perbandingan Perencanaan Pondasi Tiang Pancang Menggunakan Berbagai Macam Metode Pada Proyek Apartemen The Frontage Surabaya. Institut Teknologi Surabaya 10 November 2017.

Bowles JE (1991). Analisa dan desain Pondasi (Edisi keempat Jilid 1). Jakarta: Erlangga.

Bowles JE (1993). Analisa dan desain Pondasi (Edisi keempat Jilid 2). Jakarta: Erlangga.

Bowles JE (1996). Foundation Analysis and Design. Tokyo, Japan: McGraw-Hill Kogakusha, Ltd.

Das MB (1991). Principles of Foundation Engineering (Fourth Edition). Sacramento: California State University.

Ferra Fahriani, Yayuk Apriyanti. 2017. Analisis Daya Dukung Tanah Dan Penurunan Pondasi Pada Daerah Pesisir Pantai Utara Kabupaten Bangka Universitas Bangka Belitung. Juitech 01:01. PIssn: 2580-4057. E-Issn: 2597-7261.

Ferry Rizki Adhi Pratomo, Sri Prabandiyani R.W.Siti Hardiyati, 2014. Perancangan Pondasi Tiang Pancang Dermaga Packing Plant Banjarmasin-Kalimantan Selatan. Jurnal Karya Teknik Sipil Volume 3, Nomor 1

Hardiyatmo HC (1996). Teknik Pondasi 1. Jakarta: PT. Gramedia Pustaka Umum.

Hardiyatmo HC (2002). Teknik Pondasi 2 (Edisi Kedua). Yogyakarta: Beta Offset.

Mutia Suharlin Putri1,A, Yayuk Apriyanti1, Dan Ferra Fahriani1. Analisis Perbandingan Daya Dukung Dan Penurunan Tiang Pancang Tunggal Dengan Metode Statik Dan Uji Beban. Prosiding Seminar Nasional Penelitian \& Pengabdian Pada Masyarakat, Isbn: 978-602-61545-0-7.

Price, G \& Wardle, I. F. 1982. A comparison between cone penetration test results and the performance of small diameter instrumented piles in stiff clay. In: Proceedings of the $2^{\text {nd }}$ European symposium.

Victor Mamangkey Turangan A.E, Lanny Manaroinsong . (Analisis Pondasi Tiang Pancang Pada Silo Semen Tonasa). Fakultas Teknik, Jurusan Sipil, Universitas Sam Ratulangi Manado. 